\title{
The effect of a mental training program on enhancing some mental skills, kinematic variables and Kata performance level for Karate juniors \\ *Dr/ Ahmed Samir Yousef Abdelaziz
}

The Introduction and the Research problem:

One of the most important approaches to the study of sports is sports psychology, Where the psychological factor is the crucial variable in sports performance despite the scientific progress in the preparation of players physically, skillfully and schematically, For its effective contribution and its obvious impact on performance and motor performance, Where the success of players in sports competitions was linked to their ability to overcome all psychological pressures in various environmental conditions surrounding them to be an indicator of the integrated preparation of the player in all physical, technical, planning and psychological aspects.

Adnan Yousef (2004) asserts That psychology is one of the sciences from which the science of sports training derives information and scientific theories applicable in the field of sport, Mohamed Shamoun, Majida Ismail (2001) Indicates To superiority In the sports field requires full integration between mind and body for the flow of the maximum physical and mental energy that the player can benefit from in achieving the goals required to accomplish the required motor duty. (14:11) (19: 57)

$$
\text { Massad Al-Ayouti }
$$
(2004) explains according to Jack Liewellyn That there are two main aspects relied on in increasing the efficiency and effectiveness of motor performance during the training process are the physical aspect of skill and mental side, Mental preparation is not a substitute for physical preparation, but the integration between them is

" Lecturer at Sport Kinesiology Department, Faculty of Physical Education Mansoura University. 
the way to develop motor performance and raise it in sports competition,

Mohammed Alawi (2002), Jaclyn L Salzwedel (2009) It was agreed That the most important factors for the success of players at the international level is their abilities and psychological skills in the convergence to a large degree in their physical, motor and planning. (22: 10) (20: 198) (32: 5)

Mohamed Shamoon (2001), Vauly \&Grean Leaf ( ( $^{r \cdot \cdots}$ ), Abdul Hakim Rizk (2010) They add The integration of mental, physical and skill aspects is crucial when achieving a sense of greater self-confidence and focusing on the positive aspects that better predict performance, It also prevents negative perception that harms performance through negative emotions that cause increased anxiety, and failed expectations that reduce chances of success. (18: 29) (39: 248) (12: 73)

The researcher sees That players have the necessary mental skill Provides the most positive personality traits of karate athletes to achieve the highest levels of athletic achievement, And agree with that Nishiyama \& Brown (1998) That mental skills are an important and necessary factor to improve the performance in karate where two or more competitors compete with the strongest psychologically closest to winning taking into account the physical and technical aspects. (36: 20)

The mental skills that Kata players in karate must learn and train in the context of psychological preparation are limited to skills of relaxation, perception and attention, Where the success of the effectiveness of mental training depends on how well the player mastered the relaxation skill, which is the main entrance to recall mental images associated with the activity, Therefore mental training works as a strategy to use this mental image and use it to serve sports performance. (16: 51, 169, 228, 279) $(20: 195,196)$

The importance of performance in the Kata Competition is demonstrated by its high physical, professional and mental abilities, Represented in high strength and speed and a high 
degree of compatibility of mind and body in the performance of the kata, which performs at varying speeds and successive and continuous with the maintenance of the state of Zanshin Zanshin, a complete awareness and the spirit of combat with the transition from one movement to another smoothly, Where both Confirms Mohamed El-Arabi (1996), Nagel, C, F (2002) The importance of concentration, presence, mental presence, introspection and constant communication of players, especially Kata players, as one of the main and important aspects to overcome their opponents, So that the player Kata in the case of a full understanding of all the performance gaps in the kata of the conditions and movements and the amount of power and the ideal angles of the body's links with the aesthetic form at every moment of performance so as not to lose communication between mind and body and skill and innovation. (16: 228) (35: 179)

Ahmed Ibrahim, Atef Abaza (2005) with Kanazawa (1988) It agrees That the basic conditions are the backbone of kata players in karate, As it provides the player the ability to move and performance of defensive skills and attack from different situations in a synchronous and successive in different directions and speeds and in a logical sequence in which the player can perform the Katat maximum impact possible. (4: 157) (31:22)

According to the nature of kata performance requirements in karate, it is necessary to move quickly and achieve proper distances while performing kata (moves from one position to another) While maintaining the ideal angle of the links to combine the beauty and strength of performance "one of the basic criteria for assessing the kata" (41), The researcher studied the effect of mental training on some variables, including kinematic variables for kata players, which express objectively the extent of the development of the performance of the players and the extent of the development of mental skills for players to take the optimal motor situations.

Where both confirm Talha Hossam Eddin (1994), Adel Abdul Basir (1998), 
Andrew Little (2001)

Biomechanics is interested in studying the movement of the motion, its features and the angles of joints So you can achieve a skillful level of skill, As a study Kinematic as a branch of biomechanics for athletic performance gives honest information and real and non-speculative indicators on the level of motor performance that can be relied upon to improve the technical performance of kinetic skills, So the trainer must have a great deal of information about biomechanics through which he can benefit in building mental training and training programs on real scientific bases that make him more accurate in his work and contribute to the upgrading of the skill level. (9: 94) (11:213) (27: 12)

The problem is this research $\mathrm{n}$ the observation of the researcher during his continuous and permanent presence in the stadium as a former player and then coach, lecturer and referee of the Egyptian Karate Federation, And continuous follow-up to the development of professional levels in karate sport (kata) Most found that coaches They are interested in developing physical aspects to a great extent, As well as the technical performance of the kata without giving consideration or attention to the psychological preparation of the players " Their ability to deal with environmental and situational changes in various tournaments" Which was one of the Winning standards in many competitions, Where Kata players need to remember, visualize and retrieve the serial and sequential motor skills which are considered to be the nature of Kata's skillful motor performance, This is the researcher's motivation To study the effect of mental training and the development of mental skills on kinematic variables and the degree of performance of players for kata in karate.

The researcher chose the kata Gojushiho- sho kata According to the study that the researcher analyzed the European Championship 2017 (Youth - youth - men) for 154 players and guided by the study of Ahmed Sheikh (2016), Where it was Kata 
Gogoshihoshu was repeated with 32 repetitions by $15.02 \%$ to be the highest percentage of repeated katats in the European Championship, 14 (14) kata with 213 recurrences. Attachment (3)

And through the reference survey The researcher found some studies focused on knowledge Effect of training programs and mental perception on the performance level in karate sport especially kata, But to the knowledge of the researcher Scientific research is scarce Which deals with the impact of a mental training program on kinetic variables and the performance level of kata under study, And some mental aspects of emerging karate players Under 14 years.

\section{The Research aim :}

The research aims to Recognition The effect of mental training program on the development of some mental skills, Kinematics variables and the level of performance of kata for Karate juniors, and that is through :-

* Identify the impact of the mental training program on the development of some mental skills (relaxation, mental perception, concentration of attention) of kata for Karate juniors.

* Identify the effect of Mental training program on the development of the performance and performance of the performance of the feet (Zenktsudatchi - Kokotsudashi - Kibadashi) of kata for Karate juniors.

* Identify the effect of Mental training program On some Kinematics variables of the "Gojushiho-kata .

* Identify the effect of Mental training program On The skillful performance of the "Gojushiho-kata.

\section{The Research Hypotheses :}

There are statistically significant differences between the pre-test and post test measurement favour post test measurement of kata for Karate juniors " The research sample" In each of the :-

* Mental skills (relaxation, mental perception, concentration of attention).

* Endure performance Variables, And the skillful performance of the legs (Zenktsudashi-KokotsudashiKepadashi).

* Kinematic variables Of transitional movements For Gojushiho Kata. 
* The level of skill performance For Gojushiho Kata

\section{Procedures of The Research:} The Research Curriculum:

The researcher used The Experimental Curriculum Following Experimental method using (pre-test and post test) For One Group Design.

The Research Sample:

The researcher chose The Main Sample In The Purposive Method Of the Kata juniors in karate sport under
(14) years, Nasiriyah Sports Club Mansoura - Dakahlia Governorate, It reached (15) juniors Registered in the Egyptian Karate Federation for the sports season (2017), Been the work of homogeneity of the sample as shown in Table (1)

The number was The

Exploratory Sample (10) juniors, They were randomly selected from within the research community and outside the basic study sample.

Table (1)

Homogeneity of the research sample

\begin{tabular}{c|c|c|c|c|c}
\hline \hline Variables & $\begin{array}{c}\text { Unit of } \\
\text { measure }\end{array}$ & Mean & Median & $\begin{array}{c}\text { Std. } \\
\text { Deviation }\end{array}$ & $\begin{array}{c}\text { Coefficient } \\
\text { of Skewness }\end{array}$ \\
\hline \hline Age & $($ year) & 13.47 & 13.00 & 0.52 & 0.15 \\
\hline Height & $(\mathrm{cm})$ & 153.80 & 152.00 & 7.30 & -0.25 \\
\hline Weight & $(\mathrm{kg})$ & 52.87 & 52.00 & 7.41 & -0.52 \\
\hline Age training & (year) & 6.73 & 6.00 & 1.28 & -0.13 \\
\hline Level of intellect & Degree & 32.87 & 33.00 & 4.82 & -0.58 \\
\hline \hline
\end{tabular}

Shown in Table (1) that the Coefficients of Skewness for selected variables confined between $( \pm 3)$ and this indicates that the distribution of the sample.

The Research Tools :

First/ measurements and tests used: Attachments (1)

- Rest meter to measure the total length of the body to the nearest $(\mathrm{cm})$.
- Medical balance to measure the weight of the nearest (grams).

- Measure the general muscular capacity of the right foot (test distance of 3 right flaps). (24: 63)

- Measure the general muscular capacity of the left foot (test distance 3 left flaps). (24: 63)

- Bearing performance of STANCES in the "kata" (stability), A team of (5) Kata referees evaluate the performance of the player (Zinketsudashi-Kokotsudashi- 
Kepadashi) in the Kata for $1 \mathrm{~s}$. $(2: 6)$

- Bearing performance of STANCES in the "kata" (by moving), A team of (5) Kata referees evaluate the performance of the player (Zinketsudashi-Kokotsudashi-
Kepadashi) in the Kata for $1 \mathrm{~s}$. $(2: 6)$

The researcher was selected for the positions under study, According to the quantitative analysis of position and movements in Gojushiho-sho kata under study. Attachments (4)

Table (2)

\section{Quantitative analysis of the most important position rates of} movements in Gojushiho- sho kata

\begin{tabular}{|c|c|c|c|c|}
\hline \multicolumn{5}{|c|}{ " Gojushiho- sho kata } \\
\hline \multicolumn{5}{|c|}{ otal number of movements $=66$} \\
\hline \multicolumn{3}{|c|}{ Attack skills $=42$ movement $/ 64 \%$} & \multicolumn{2}{|c|}{ Defense skills $=24$ movements / $36 \%$} \\
\hline $\begin{array}{c}\text { Direction of } \\
\text { movement }\end{array}$ & $\begin{array}{c}\text { Type of } \\
\text { skill }\end{array}$ & $\begin{array}{c}\text { the } \\
\text { number }\end{array}$ & $\begin{array}{c}\text { Ratio to skill } \\
\text { type }\end{array}$ & $\begin{array}{c}\text { ratio of total } \\
\text { kata }\end{array}$ \\
\hline \multirow{2}{*}{ Forward } & Attack & 14 & $\% \Gamma \cdot .9$ & $\% 19 . \mathrm{V}$ \\
\hline & Defense & $\varepsilon$ & $\% 17 . \mathrm{V}$ & $\% 7.1$ \\
\hline \multirow{2}{*}{ backwards } & Attack & - & - & - \\
\hline & Defense & $r$ & $\% 1 Y .0$ & $\% \leq .0$ \\
\hline \multirow[t]{2}{*}{ in the place } & Attack & 14 & $\% r \cdot .9$ & $\% 19 . \vee$ \\
\hline & Defense & V & $\%$ Y 9.4 & $\% 1 \cdot .7$ \\
\hline \multirow{2}{*}{$\begin{array}{l}\text { To the } \\
\text { right side }\end{array}$} & Attack & $\varepsilon$ & $\% 9.0$ & $\% 7.1$ \\
\hline & Defense & 1 & $\% \leq . Y$ & $\% 1.0$ \\
\hline \multirow{2}{*}{$\begin{array}{l}\text { To the left } \\
\text { side }\end{array}$} & Attack & $V$ & $\% 17 . \vee$ & $\% 1 \cdot .7$ \\
\hline & Defense & 1 & $\% \varepsilon . Y$ & $\% 1.0$ \\
\hline \multirow{2}{*}{ Angle 90} & Attack & 1 & $\%$ Y.乏 & $\% 1.0$ \\
\hline & Defense & $r$ & $\%$ YY.० & $\% \leqslant 0$ \\
\hline \multirow{2}{*}{ Angle 180} & Attack & 1 & $\%$ Y.乏 & $\% 1.0$ \\
\hline & Defense & $\varepsilon$ & $\% 17 . V$ & $\% 7.1$ \\
\hline
\end{tabular}


Table (3)

Quantitative Analysis The most important position rates are in Gojushiho-sho kata

Total number of positions in Kata Gogoshiho = 63

Attack skills = 42 movements By 64\% $\quad$ Defensive skills= 24 moves By $36 \%$

\begin{tabular}{l|c|c|c|c|c}
\hline position & number & Percentage & position & number & Percentage \\
\hline \hline ZhenkutsuDachi & r & $\% \leq r .9$ & Kokotsu Dachi & $1)$ & $\% 17.46$ \\
\hline Kiba Dachi & $q$ & $\% 14.3$ & Voodoo Dachie & $r$ & $\% 3.17$ \\
\hline Ashi Dachi & $\mathrm{V}$ & $\% 11.11$ & KozaDaqi & $\varepsilon$ & $\% 6.35$ \\
\hline NekwachiDachi & $\mathrm{Y}$ & $\% 1.59$ & Chizen Tai & $\mathrm{r}$ & $\% 3.17$ \\
\hline \hline
\end{tabular}

- Illustrated Intelligence Test (1978) prepared by Ahmed Zaki Saleh. Attachments (5)

- Mental training tests prepared by Nidfer (1985), Arabization of Mohammed Al-Arabi Chamoun, and Majda Muhammad Ismail (1996). Attachments (5)

The researcher chose Gojushiho- sho kata According to the study that the researcher analyzed the European Championship 2017 and guided by the study of Sheikh Ahmed (2016) (2), A total of (14) different kata were performed over the course of the tournament with a total of - Card of the levels of muscle tension- Mental perception scale in the sports field Network testing to focus attention- self-interview questionnaire test. Attachments (5)

- Skill performance test For Gojushiho- sho kata 213 times. The most important katate percentages were in the European Championship according to the results of the European championship analysis in Table (4). Attachments (3)

Table (4)

The percentage of the most frequent five katats in the 2017 European Championship (juniors - Youth - men) with 154 players

\begin{tabular}{c|c|c|c}
\hline \hline m & $\begin{array}{c}\text { Name of Kata executed } \\
\text { during the tournament }\end{array}$ & $\begin{array}{c}\text { Total performance } \\
\text { of the Kata }\end{array}$ & $\begin{array}{c}\text { percentage } \\
\text { of total }\end{array}$ \\
\hline \hline$-r$ & Gojushiho- sho & $r r$ & $\% 15.02$ \\
\hline$-r$ & Shatniara Kushanko & $r \cdot$ & $\% 14.08$ \\
\hline$-r$ & Kankosho & $r \cdot$ & $\% 14.08$ \\
\hline$-\varepsilon$ & Ansso & $r \wedge$ & $\% 13.15$ \\
\hline-0 & Super Imbi & $r \xi$ & $\% 11.27$ \\
\hline \hline
\end{tabular}

Assiut Journal For Sport Science Arts 
* Second/ Kinetic parameters: Attachment (7)

According to the analysis of the situations, movements and trends of Gojushiho- sho kata, the researcher identified the conditions and direction of the movement in which the Kinematic analysis was applied as follows: - Form (1) (2) (3)

* From Zenkutsu Dachi to Zenkutsu Dashi positionfrom moving forward.

* From Kokotsu Dachi to Kokotsu Dashi from moving forward.

* from Zenkutsu Dachi to Kiba Dashi from moving forward in turn 180.

The researcher used three-dimensional Kinematics analysis to measure kinetic variables, And the use of 2 digital video camera Panasonic 60 cadres / second, The camera was placed on a tripod at 1.10 meters and at a distance of 4 meters to determine the range of situations and movements, The calibration box is made of $1 \mathrm{mx} 1 \mathrm{~m} 2 \mathrm{~m}$ metal painted black and white in front of the camera, The analysis was carried out by the Simi motion program after dividing the transitional conditions into three stages with four moments, Were choice It is the phase Push to start moving (instant End of the push to move to the first position of the standby mode), the phase Connectivity movement (instant End of the first position + the instant the end of the Push "leave" to move to the second position), Stability phase (instant of the end performance of the second move).

The researcher chose The following Kinematic variables are studied at previous instant, After the contribution of the Kinematic parameters of the anatomical points (pelvic-knee-ankle-foot) The most influential in the degree of performance of players of the position and movements of art selected of kata for Karate juniors. Table (5)

Angle offset - linear velocity linear displacement - linear wheel - angular velocity 
Table (5)

The contribution of Kinematic indicators in the effectiveness of the performance of the positions and movements of kata for Karate juniors

\begin{tabular}{|c|c|c|c|c|}
\hline phase & $\begin{array}{l}\text { Anato } \\
\text { mical } \\
\text { point }\end{array}$ & variable & $\begin{array}{c}\text { Partial } \\
\text { correlation } \\
\text { coefficient }\end{array}$ & $\begin{array}{l}\text { Contribut } \\
\text { ion Ratio }\end{array}$ \\
\hline \multirow{4}{*}{$\begin{array}{l}\text { Push- } \\
\text { To start } \\
\text { moving }\end{array}$} & \multirow[t]{2}{*}{$\overline{~ h i p ~}$} & right hip Z & -0.606 & $\% 36.72$ \\
\hline & & right hip angle $\mathrm{X}$ & -0.436 & $\% 19.01$ \\
\hline & knee & left knee $\mathrm{a}(\mathrm{Z})$ & 0.336 & $\% 11.29$ \\
\hline & ankle & right ankle-bone $\mathrm{V}(\mathrm{Y})$ & 0.257 & $\% 6.60$ \\
\hline \multirow{4}{*}{$\begin{array}{l}\text { Connecti } \\
\text { vity } \\
\text { moveme } \\
\text { nt }\end{array}$} & \multirow{3}{*}{ hip } & right hip Z & -0.777 & $\% 60.37$ \\
\hline & & right hip angle $\mathrm{X}$ & -0.664 & $\% 44.09$ \\
\hline & & left hip angle $v(X)$ & 0.565 & $\% 31.92$ \\
\hline & knee & left knee Y & 0.464 & $\% 21.53$ \\
\hline \multirow{5}{*}{ Stability } & hip & left hip a(Z) & -0.72 & $\% 51.84$ \\
\hline & \multirow[b]{2}{*}{ knee } & right knee Y & -0.61 & $\% 37.21$ \\
\hline & & left knee a $(Z)$ & 0.461 & $\% 21.25$ \\
\hline & \multirow[t]{2}{*}{ ankle } & left ankle-bone $\mathrm{v}(\mathrm{Y})$ & -0.56 & $\% 31.36$ \\
\hline & & right ankle-bone Y & -0.4 & $\% 16$ \\
\hline
\end{tabular}

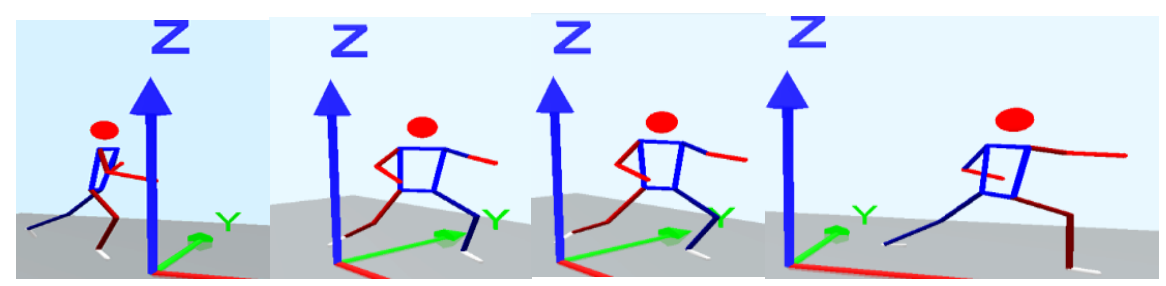

Figure (1) Zhenkutsu Dachi to Zinkutsu Dashi
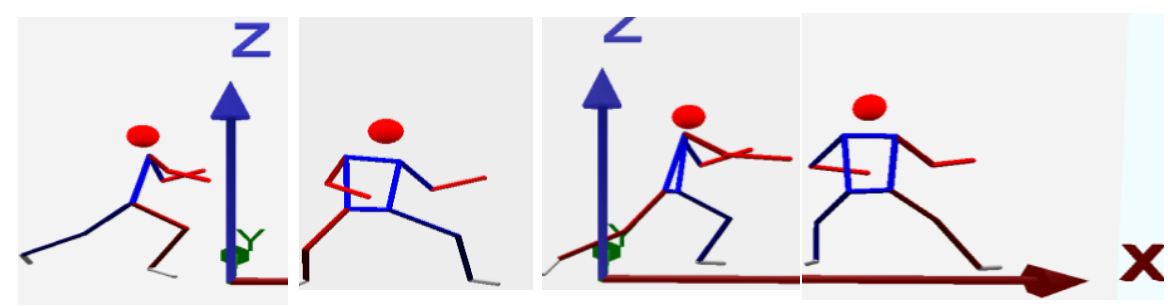

Figure (2) From Kokotsu Dachi to Kokotsu Dashi 

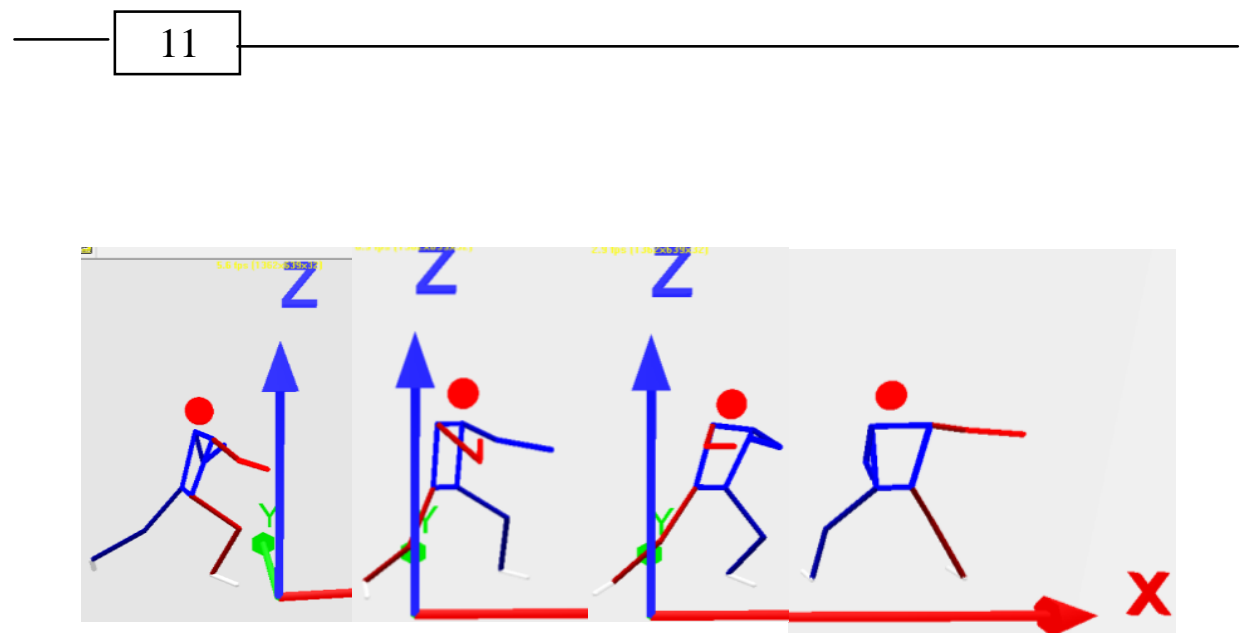

Figure (3) From the position of Zhenkutsu Dachi to Kiba Dash

Third / The Scientific

Coefficient Of The Test:

The

scientific

coefficients (Validity and

Reliability) of the physical and skill tests under study were calculated using the validity of

the differentiation to verify the validity of the tests and the method of application of the test and its re-test to the stability account as shown in Table (6), (7)

Table (6)

Indication of differences between the characteristic group and the non - characteristic group in the tests under study

\begin{tabular}{|c|c|c|c|c|c|c|c|}
\hline \multirow{2}{*}{$\begin{array}{c}\text { Variables } \\
\mathrm{N} 1=\mathrm{N} 2=10\end{array}$} & \multirow{2}{*}{$\begin{array}{l}\text { Unit of } \\
\text { measure }\end{array}$} & \multicolumn{2}{|c|}{$\begin{array}{l}\text { Featured } \\
\text { Group }\end{array}$} & \multicolumn{2}{|c|}{$\begin{array}{c}\text { unmarked } \\
\text { group }\end{array}$} & \multirow[t]{2}{*}{ t-value } & \multirow[t]{2}{*}{ Sig } \\
\hline & & Mean & Std. $D$ & Mean & Std. D & & \\
\hline Distance 3 rounds right & $\overline{\mathrm{m}}$ & 4.47 & 0.47 & 3.21 & 0.69 & $* 4.77$ & $\overline{0.001}$ \\
\hline Distance 3 rounds left & $\mathrm{m}$ & 4.44 & 0.39 & 2.88 & 0.44 & $* 8.35$ & 0.001 \\
\hline \multicolumn{8}{|c|}{ Bearing The performance of the two legs of the "stability" } \\
\hline Zinktsodachi & (sec.) & 40.70 & 8.54 & 27.60 & 5.93 & $* 3.99$ & $\overline{0.001}$ \\
\hline Kokotsudashi & (sec.) & 41.80 & 6.75 & 27.40 & 4.27 & $* 5.70$ & 0.001 \\
\hline Kiba Dachi & (sec.) & 39.60 & 5.76 & 29.70 & 6.25 & $* 3.68$ & 0.002 \\
\hline \multicolumn{8}{|c|}{ The level of skillful performance of the "positio of movement } \\
\hline$\overline{\text { Zinktsodachi }}$ & Degree & 6.60 & 0.51 & 3.38 & 0.46 & $* 13.87$ & 0.001 \\
\hline Kokotsudashi & Degree & 6.54 & 0.55 & 3.37 & 0.62 & $* 12.132$ & 0.001 \\
\hline Kiba Dachi & Degree & 6.41 & 0.64 & 3.53 & 0.52 & $* 11.07$ & 0.001 \\
\hline \multicolumn{6}{|c|}{ Tabular value at a significant level of $0.05=1.833$} & $\mathrm{D} *$ & \\
\hline
\end{tabular}




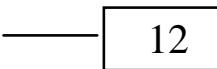

Table (6) shows statistically significant differences between the Featured Group and the

Table (7)

unmarked group group in favor of the characteristic group in the tests under study, indicating the validity of these variables.

Reliability Of The Test $\mathbf{n}=\mathbf{1 0}$

\begin{tabular}{|c|c|c|c|c|c|c|}
\hline \multirow{2}{*}{ Variables N $1=10$} & \multirow{2}{*}{$\begin{array}{c}\text { Unit of } \\
\text { measure }\end{array}$} & \multicolumn{2}{|c|}{ The first test } & \multicolumn{2}{|c|}{ The second test } & \multirow{2}{*}{$\begin{array}{c}\text { correlation } \\
\mathbf{r}\end{array}$} \\
\hline & & Mean & Std. D & Mean & Std. D & \\
\hline Distance 3 ro & $\mathrm{m}$ & 4.47 & $\overline{0.47}$ & 4.52 & $\overline{0.41}$ & $* 0.82$ \\
\hline Distance 3 rounds left & $\mathrm{m}$ & 4.44 & 0.39 & 4.34 & 0.49 & $* 0.77$ \\
\hline
\end{tabular}

Bearing The performance of the two legs of the "stability"

\begin{tabular}{l|c|c|c|c|c|c}
\hline \hline Zinktsodachi & (sec.) & 40.70 & 8.54 & 41.30 & 6.20 & $* 0.87$ \\
\hline Kokotsudashi & (sec.) & 41.80 & 6.75 & 40.30 & 7.80 & $* 0.79$ \\
\hline Kiba Dachi & (sec.) & 39.60 & 5.76 & 40.30 & 5.76 & $* 0.82$ \\
\hline \hline
\end{tabular}

The level of skillful performance of the "positio of movement

\begin{tabular}{l|c|c|c|c|c|c}
\hline \hline Zinktsodachi & Degree & 6.60 & 0.51 & 6.72 & 0.36 & $* 0.78$ \\
\hline Kokotsudashi & Degree & 6.54 & 0.55 & 6.55 & 0.51 & $* 0.72$ \\
\hline Kiba Dachi & Degree & 6.41 & 0.64 & 6.56 & 0.63 & $* 0.84$ \\
\hline \hline
\end{tabular}

Value at a significant level $0.05=0.549$

Table (7) that there is a positive correlation relationship between the first application and the second application in the variables under study, indicating the stability of the variables under consideration.

Fourth/The proposed mental training program:

- The scientific criteria for selecting the mental skills of kata karate players to be used in the proposed mental training program under study were determined by an expert opinion poll on the identification of the most important mental skills to be included in the proposed mental training program under study. Attachments (2)

- The main aspects of the proposed mental training program were determined by the number of units and the time plan (the total time of the program, the number of training sessions per week, the time of the training unit) through the expert consultation form. Attachments (6)

- The researcher reached the period of application of mental units (12) weeks by three mental units per week (30) minutes per unit, the total number of units (36) training unit and the number of mental training hours in the program (18) hours (1080) minutes. Attachments (8) 
table (8)

Percentage of temporal distribution of the proposed program dimensions for mental training

\begin{tabular}{l|c|c|c}
\hline \hline Program dimensions & $\begin{array}{c}\text { Number of } \\
\text { units }\end{array}$ & $\begin{array}{c}\text { Total time } \\
\text { per minute }\end{array}$ & Percentage \\
\hline \hline Muscle relaxation & 36 & 540 & $50 \%$ \\
\hline Mental perception & 24 & 360 & $33.3 \%$ \\
\hline Concentration of attention and self talk & 12 & 180 & $16.7 \%$ \\
\hline Total & ------ & 1080 & $100 \%$ \\
\hline \hline
\end{tabular}

table (9)

Distribution of components of the proposed mental training program

\begin{tabular}{|c|c|c|c|c|c|}
\hline $\begin{array}{l}\text { Components } \\
\text { of the unit }\end{array}$ & $\begin{array}{l}\text { Number } \\
\text { Unit }\end{array}$ & The way & Dimensions & Weeks & Stages \\
\hline $\begin{array}{c}\text { Muscle } \\
\text { relaxation }\end{array}$ & 3 & $\begin{array}{c}\text { Delayed } \\
\text { relaxation }\end{array}$ & $\begin{array}{l}\text { Muscle } \\
\text { relaxation }\end{array}$ & the first & \multirow{4}{*}{ 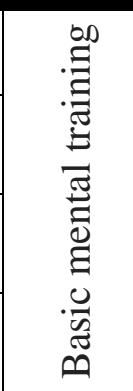 } \\
\hline $\begin{array}{c}\text { Muscle } \\
\text { relaxation }\end{array}$ & 3 & $\begin{array}{c}\text { Breathing } \\
\text { control }\end{array}$ & $\begin{array}{c}\text { Mental } \\
\text { relaxation }\end{array}$ & $\begin{array}{l}\text { The } \\
\text { second }\end{array}$ & \\
\hline $\begin{array}{l}\text { Mental } \\
\text { relaxation }\end{array}$ & & $\begin{array}{l}\text { Delayed } \\
\text { relaxation }\end{array}$ & $\begin{array}{c}\text { Muscle and } \\
\text { mental relaxation }\end{array}$ & $\begin{array}{l}\text { third- } \\
\text { fourth }\end{array}$ & \\
\hline $\begin{array}{l}\text { Muscle } \\
\text { relaxation }\end{array}$ & 6 & $\begin{array}{c}\text { Breathing } \\
\text { control }\end{array}$ & $\begin{array}{l}\text { Basic mental } \\
\text { perception }\end{array}$ & And IV & \\
\hline $\begin{array}{l}\text { Mental } \\
\text { relaxation }\end{array}$ & 6 & $\begin{array}{c}\text { Image clarity } \\
\text { training and } \\
\text { visualization } \\
\text { control } \\
\end{array}$ & $\begin{array}{l}\text { Multiple } \\
\text { mental } \\
\text { perception }\end{array}$ & $\begin{array}{l}\text { Fifth } \\
\text { and } \\
\text { sixth }\end{array}$ & \multirow{3}{*}{ 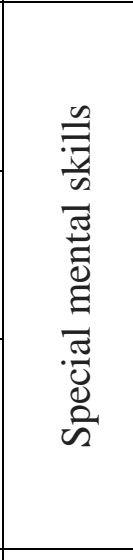 } \\
\hline $\begin{array}{l}\text { Muscle and } \\
\text { mental } \\
\text { relaxation }\end{array}$ & 6 & $\begin{array}{c}\text { Visual, auditory, } \\
\text { sensory and } \\
\text { dynamic training } \\
\text { exercises } \\
\end{array}$ & Attention & $\begin{array}{l}\text { Ninth - } \\
\text { tenth }\end{array}$ & \\
\hline $\begin{array}{l}\text { Basic mental } \\
\text { perception }\end{array}$ & 6 & $\begin{array}{l}\text { Training to select } \\
\text { attention and } \\
\text { select excitements } \\
\text { and focus } \\
\text { attention }\end{array}$ & $\begin{array}{c}\text { Mental } \\
\text { perception }\end{array}$ & $\begin{array}{l}\text { Eleventh } \\
\text { and } \\
\text { Twelfth }\end{array}$ & \\
\hline & 36 units & & & & \\
\hline
\end{tabular}

Assiut Journal For Sport Science Arts 
- Sensation of the difference between the condition of the muscles during contraction and its expansion and the succession of contraction from one muscle group to another to cover all muscle groups in the body and is called this type of muscle relaxation "sequential". - Use the linking of symbols (inspiration - exhalation - rest) to reach the best possible level of mental relaxation.

- Use of interaction between the dimensions of mental perception (visual - auditory sense of movement - emotional - control perception) to reach the best level of mental perception of skills.

- Use the internal and external focus method to achieve the best level of concentration in important aspects during performance.

\section{Measures :}

Measurement of Kinematics variables: - The researcher analyzed the kinetic dynamics of kinetic variables in the selected movements of Kata karate in the period from Friday, 13/10/2017 to Sunday, 19/11/2017.

Tribal measurement:

The application was carried out by measuring the mental skills tests (relaxation, mental perception, concentration of attention), Performance variables and the skill level of the legs of the legs (ZinktsudashiKokotsudashi-Kepadashi), Kinematic variables of the kinetic motions Gojushihoshokata, And the skill level of the kinetic sentence Gojushiho-sho kata, For the sample of the research, as of Wednesday, 22/11/2017 and until Monday, 27/11/2017.

Application of mental training program: Attachment (8)

The mental training program was implemented for 12 weeks with three units per week during the period from Monday 4/12/2017 to Saturday, 3/3/2018. The training units of the program were performed before the period of physical and skilled training for juniors

Second measurement ;

The

Second measurement was carried out on Tuesday, March 6, 2018 until Sunday, 11/3/2018, to compare it with tribal measures in the same procedures and previous circumstances using appropriate statistical means. 
Statistical processing: The following statistical transactions were used using the statistical program, 2010 Excel, SPSS / 20: - SMA. standard deviation. - Mediator. - Correlation coefficient.
Multiple linear regression. Partial correlation coefficient Presenting The Results:

- Presentation of the results of the differences between the pre - measurement and the Post measurement of the research group.

\section{Table (11)}

The differences between the pre - measurement and the Post measurement For the research group on physical variables, Carrying performance, And the skillful performance of the feet, The performance score Gojushiho-sho kata is under search $\mathrm{N}=15$

\begin{tabular}{l|c|c|c|c|c|c|c}
\hline \hline \multirow{2}{*}{ the test } & \multirow{2}{*}{$\begin{array}{c}\text { measruing } \\
\text { unit }\end{array}$} & \multicolumn{2}{|c|}{$\begin{array}{c}\text { pre - } \\
\text { measurement }\end{array}$} & \multicolumn{2}{c|}{$\begin{array}{c}\text { Post } \\
\text { measurement }\end{array}$} & \multirow{2}{*}{ t } & \multirow{2}{*}{ Sig } \\
\cline { 3 - 6 } & & Mean & $\begin{array}{c}\text { Std. } \\
\text { D }\end{array}$ & Mean & $\begin{array}{c}\text { Std. } \\
\text { D }\end{array}$ & & \\
\hline \hline $\begin{array}{l}\text { Distance 3 } \\
\text { rounds right }\end{array}$ & $\mathrm{M}$ & 3.73 & 0.56 & 4.65 & 0.49 & 10.095 & 0.001 \\
\hline $\begin{array}{l}\text { Distance 3 } \\
\text { rounds left }\end{array}$ & $\mathrm{M}$ & 3.71 & 0.59 & 4.45 & 0.50 & 7.299 & 0.001 \\
\hline \hline
\end{tabular}

\begin{tabular}{l|c|c|c|c|c|c|c}
\hline \multicolumn{2}{l}{ Carrying performance of the two legs of the "stability" } \\
\hline \hline Zinktsodachi & second & 29.53 & 7.25 & 39.73 & 9.37 & 8.586 & 0.001 \\
\hline Kokotsudashi & second & 28.47 & 4.22 & 41.60 & 6.75 & 4.928 & 0.001 \\
\hline Kiba Dachi & second & 28.47 & 4.34 & 46.67 & 8.08 & 12.483 & 0.001 \\
\hline
\end{tabular}

\begin{tabular}{l|c|c|c|c|c|c|c}
\hline The level of skillful performance of the two legs of the " movement" \\
\hline \hline Zinktsodachi & degree & 5.93 & 0.45 & 7.84 & 0.46 & 28.661 & 0.001 \\
\hline Kokotsudashi & degree & 5.23 & 0.59 & 7.27 & 0.59 & 25.202 & 0.001 \\
\hline Kiba Dachi & degree & 5.37 & 0.60 & 7.37 & 0.58 & 17.078 & 0.001 \\
\hline \hline Kata degree & degree & 5.50 & 0.57 & 7.58 & 0.55 & 26.000 & 0.001 \\
\hline \hline
\end{tabular}

Value $t$ The table is at the level of $0.05=1.761 \quad *=\mathrm{D}$.

Table (11) shows that there are statistically significant differences between(the pre - measurement and the Post measurement) for the benefit of post- measurement in the physical variables and the level of performance of the skills of the position Of the movement, The skill level of Kata Gogoshiho is under consideration, Where the 
calculated $\mathrm{T}$ value is above its tabular value at a significant level of 0.05 .

These results indicate a clear and significant improvement in the physical variables and the skill level of the research in the research sample, Indicating the impact of the training program that has been implemented and which has made a positive change in the physical variables and the level of skill performance under consideration.

Pre-test

Post-test

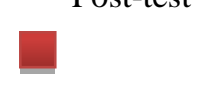

-

Figure (4) Average pre

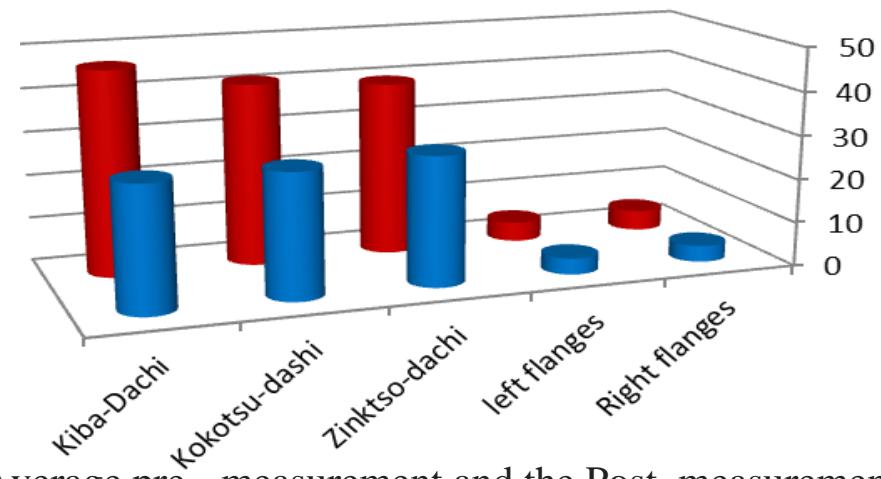

research group in the physical variables and man performance performance leos of "stahilitv"

Pre-test

Post-test

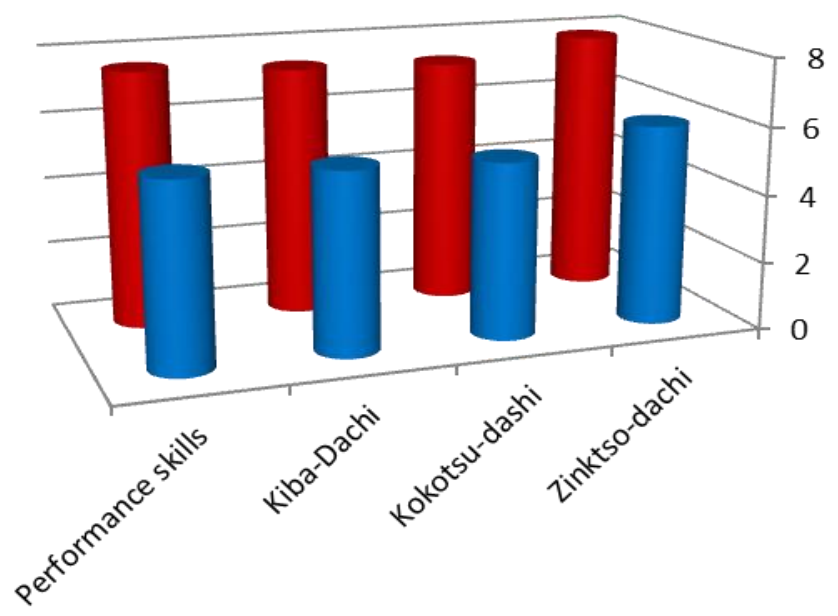

Figure (5) Average pre - measurement and the Post measurement For the research group in the skill level

Assiut Journal For Sport Science Arts 


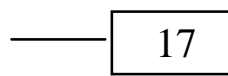

Table (12)

The differences between the pre - measurement and the Post measurement For the research group In mental skills (muscular relaxation, mental perception, concentration of attention, selftalk) $(\mathbf{n}=\mathbf{1 5})$

\begin{tabular}{|c|c|c|c|c|c|c|c|c|}
\hline \multirow{2}{*}{\multicolumn{2}{|c|}{ Measurement }} & \multirow{2}{*}{$\begin{array}{c}\text { measruing } \\
\text { unit }\end{array}$} & \multicolumn{2}{|c|}{$\begin{array}{c}\text { Pre - } \\
\text { measurement }\end{array}$} & \multicolumn{2}{|c|}{$\begin{array}{c}\text { Post - } \\
\text { measurement }\end{array}$} & \multirow{2}{*}{$\mathbf{T}$} & \multirow{2}{*}{ Sig } \\
\hline & & & Mean & $\begin{array}{c}\text { Std. } \\
\text { D }\end{array}$ & Mean & $\begin{array}{c}\text { Std. } \\
\text { D }\end{array}$ & & \\
\hline \multirow{5}{*}{ 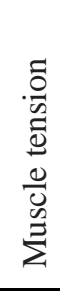 } & head & degree & 11.67 & 2.58 & 6.33 & 3.06 & 11.741 & 0.001 \\
\hline & arms & degree & 11.60 & 2.53 & 5.73 & 1.62 & 16.144 & 0.001 \\
\hline & the trunk & degree & 9.13 & 2.00 & 4.40 & 1.35 & 15.764 & 0.001 \\
\hline & Two lege & degree & 16.27 & 4.06 & 7.33 & 3.68 & 12.403 & 0.001 \\
\hline & G.tension & degree & 53.67 & 10.43 & 25.93 & 9.25 & 17.815 & 0.001 \\
\hline Tal & ing self & degree & 20.60 & 2.75 & 31.27 & 4.65 & 13.919 & 0.001 \\
\hline \multirow{5}{*}{ 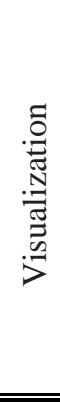 } & Optical & degree & 10.07 & 1.79 & 12.73 & 1.67 & 8.789 & 0.001 \\
\hline & Audio & degree & 8.67 & 2.32 & 12.53 & 1.51 & 7.644 & 0.001 \\
\hline & $\begin{array}{l}\text { Sensory- } \\
\text { motion }\end{array}$ & degree & 8.67 & 2.41 & 12.33 & 1.99 & 10.557 & 0.001 \\
\hline & $\begin{array}{l}\text { Emotional } \\
\text { state }\end{array}$ & degree & 9.07 & 1.58 & 12.47 & 1.68 & 12.475 & 0.001 \\
\hline & $\begin{array}{l}\text { Mental } \\
\text { perception }\end{array}$ & degree & 9.20 & 2.54 & 13.13 & 1.92 & 8.320 & 0.001 \\
\hline \multicolumn{2}{|c|}{ Focus attention } & degree & 32.73 & 4.67 & 53.93 & 4.62 & 33.441 & 0.001 \\
\hline
\end{tabular}

T. spreadsheet at $0.05=1.761$ when the degree of freedom $n-1=14$

Table (12) indicates:

There were statistically significant differences between the averages (premeasurement, postmeasurement)in the research sample In muscle tension (head, arm, trunk, legs, general tension) in favor of post measurement, Indicating a high degree of relaxation in the sample of the study, where the value of $(\mathrm{T})$ between (11.741, 17.815), a function at a significant level (0.05).

It also indicates statistically significant differences between the 
averages (pre- measurement, post- measurement)in the research sample in (Self-talk, visual perception, auditory perception, sensory perception of movement, emotional state, perception control, concentration of attention) for the benefit of postmeasurement, Where the value of $(\mathrm{T})$ between $(7.644,33.441)$ and a function at a significant level (0.05).

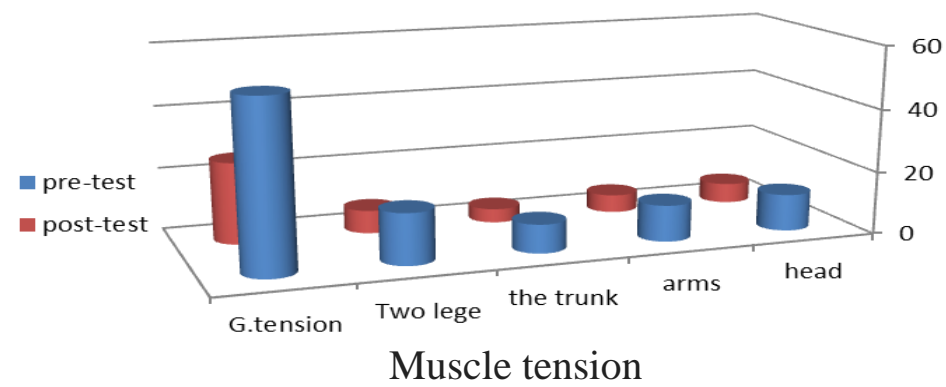

Figure (6):Mean of pre and post measurements of the research group at the level of muscular tension of the research sample

- pre-test

a post-test

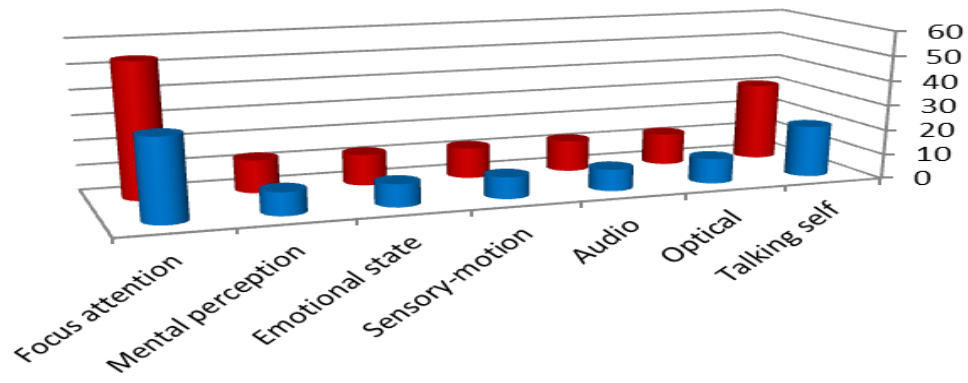

Figure (7) The average of the pre and post measurements of the research group in self - talk - mental perception - concentration of attention to the research sample 
Table (13)

Differences between the pre- and the post measurement of the dimension of the research group In the Kinematics variables of the position movement $\quad n=15$

\begin{tabular}{|c|c|c|c|c|c|c|c|}
\hline \multirow[b]{2}{*}{ Stages of skill } & \multirow[b]{2}{*}{$\begin{array}{l}\text { Anatomical } \\
\text { point }\end{array}$} & \multirow[b]{2}{*}{ Variables } & \multicolumn{2}{|c|}{ القياس القبلى } & \multicolumn{2}{|c|}{ القياس البعدى } & \multirow[b]{2}{*}{$\begin{array}{c}\text { t- } \\
\text { value }\end{array}$} \\
\hline & & & Mean & $\begin{array}{c}\text { Std. } \\
\text { D }\end{array}$ & Mean & $\begin{array}{c}\text { Std. } \\
\text { D }\end{array}$ & \\
\hline \multirow{4}{*}{$\begin{array}{l}\text { Push-To start } \\
\text { moving }\end{array}$} & \multirow[b]{2}{*}{ pelvis } & right hip Z & 1.99 & 0.39 & 0.69 & 0.78 & $* \leqslant \leqslant 0$ \\
\hline & & $\begin{array}{l}\text { right hip } \\
\text { angle X }\end{array}$ & 150.6 & 15.48 & 163.9 & 17.48 & *Y.VT \\
\hline & knee & $\begin{array}{l}\text { left knee } \\
a(Z)\end{array}$ & 0.77 & 4.48 & -1.97 & $\because A r$ & $* V . \leqslant r$ \\
\hline & ankle & $\begin{array}{l}\text { right ankle- } \\
\text { boneV(Y) }\end{array}$ & -0.52 & 0.27 & $\cdot .9 \cdot 1$ & $\because \leqslant \wedge$ & $* \Lambda . \Upsilon \wedge$ \\
\hline \multirow{4}{*}{$\begin{array}{c}\text { interconnection } \\
\text { movement }\end{array}$} & \multirow{3}{*}{ pelvis } & right hip Z & 0.64 & 0.28 & 0.70 & 0.02 & $* 0 . \leqslant 1$ \\
\hline & & $\begin{array}{l}\text { right hip angle } \\
\mathrm{X}\end{array}$ & 109.3 & 8.83 & 127.7 & 15.78 & *Y. To \\
\hline & & $\begin{array}{l}\text { left hip angle } \\
\mathrm{v}(\mathrm{X})\end{array}$ & 0.74 & 3.80 & r.46 & 1.94 & * \\
\hline & knee & left knee Y & 0.41 & 0.67 & 1.62 & 0.49 & $* V . \wedge r$ \\
\hline \multirow{5}{*}{ stability } & pelvis & left hip a(Z) & $0 . V T$ & $\because r \wedge \wedge$ & $\varepsilon . r \varepsilon$ & $\because V \leq Y$ & $* \leqslant .91$ \\
\hline & \multirow{2}{*}{ knee } & right knee $\mathrm{Y}$ & 0.74 & 0.37 & T.61 & $0 . \vee 1$ & $* 7.1 \mathrm{~V}$ \\
\hline & & left knee a(Z) & -4.94 & 4.03 & $0 . V r$ & $\cdot \Gamma \wedge \Lambda$ & *r.YY \\
\hline & \multirow{2}{*}{ knee } & $\begin{array}{l}\text { left ankle- } \\
\text { bone } \mathrm{v}(\mathrm{Y})\end{array}$ & $\varepsilon . \vee 1$ & $1.7 \varepsilon$ & 7.47 & $.10 r$ & $* r .1$ \\
\hline & & $\begin{array}{l}\text { right ankle- } \\
\text { bone Y }\end{array}$ & 0.69 & 0.08 & 1.68 & $\because \cdot r$ & *V.r \\
\hline
\end{tabular}

T. spreadsheet at $0.05=1.761$ when the degree of freedom $n-1=14$ Table (13) shows There are statistically significant differences between the pre post measurement in the Kinematics variables contributing to the degree of skill performance, For the selected movement position under search for the post measurement of the research sample, There was a significant improvement in anatomical points pelvic, knee and ankle, Indicating the moral impact of the content of the proposed mental training program on the development of the performance of the movements of the players of Gojushiho-sho kata.

As shown in table (13) There are statistically significant differences between the pre - post measurement in the Kinematics variables contributing to the degree of 
skill performance for the pre measurement For the anatomic point of the pelvis right hip $\mathrm{Z}$ in the propulsion stage - to start moving In displacement on the
$\mathrm{Z}$ vehicle, The vertical displacement of the right pelvis in the pre measurement was 1.99 degrees, and the post measurement was 0.69 degrees.

\section{Table (14)}

The relationship between mental skills (muscular relaxation, mental perception, concentration of attention, self-talk) and the performance skill of Gojushiho-sho kata $\quad(n=15)$

\begin{tabular}{|c|c|c|c|}
\hline \multicolumn{2}{|r|}{ Variables } & $\begin{array}{c}\text { measuring } \\
\text { unit }\end{array}$ & $\begin{array}{c}\text { Degree Of } \\
\text { performance skill }\end{array}$ \\
\hline \multirow{5}{*}{$\begin{array}{l}\text { Indicator } \\
\text { Of muscle } \\
\text { relaxation }\end{array}$} & Muscle tension of the head & $\overline{\text { Degree }}$ & $* 0.876$ \\
\hline & Muscle tension of the arms & Degree & $* 0.742$ \\
\hline & Tension of the trunk & Degree & $* 0.786$ \\
\hline & Muscle tension of the legs & Degree & $* 0.795$ \\
\hline & General tension & Degree & $* 0.677$ \\
\hline \multicolumn{2}{|l|}{ Talking self } & Degree & *0.691 \\
\hline \multirow{5}{*}{$\begin{array}{c}\text { Mental } \\
\text { perception }\end{array}$} & Degree & Degree & $* 0.677$ \\
\hline & Degree & Degree & $* 0.793$ \\
\hline & Degree & Degree & $* 0.692$ \\
\hline & Degree & Degree & $* 0.776$ \\
\hline & Degree & Degree & $* 0.721$ \\
\hline \multicolumn{2}{|c|}{ Focus attention } & Degree & $* 0.792$ \\
\hline \multicolumn{2}{|c|}{$\begin{array}{l}\text { Table (14) shows that } \\
\text { there is a relationship Positive } \\
\text { correlative positive correlation } \\
\text { between the variables of } \\
\text { mental skills and skill level to } \\
\text { Gojushiho-sho kata, After the } \\
\text { implementation of the } \\
\text { proposed mental training } \\
\text { program, The calculated value } \\
\text { of }(r) \text { ranged between } * 0.677 \text { : }\end{array}$} & \multicolumn{2}{|c|}{$\begin{array}{l}\text { * } 0.876 \text {, which is greater than } \\
\text { the value (r) of the table at a } \\
\text { significant level of } 0.05= \\
0.514 \text {. } \\
\text { The Results Discussion: } \\
\text { Discuss the results of the } \\
\text { physical and skill variables } \\
\text { under consideration. } \\
\text { The results of Table } \\
\text { (11) indicate There were }\end{array}$} \\
\hline \multicolumn{4}{|c|}{ Assiut Journal For Sport Science Arts } \\
\hline
\end{tabular}


statistically significant differences between the pre and post measurement for the research sample in the physical variables,

Carrying performance " Of stability and move" For the legs (Zenktsudashi-Kokotsudashi-

Kibadashi), And the degree of skill performance of Kata Gogoshiho For the post measurement, And the researcher attributed the existence of this improvement in the physical and skill variables in the research sample to the content of the mental training program under study, Where the mental training program contributed to reduce tension and develop relaxation, which in turn improved the ability of players to stimulate and use muscles to be involved in the performance skill, and thus increase the driving force of the body and raise morale and develop a sense of success and win.

$$
\text { time record The }
$$

Carrying performance position (static) For the players of the "research sample" at the beginning of the program 28.47 $\mathrm{s}$, Until the time of carrying the performance of static to 56.67 $\mathrm{s}$, It is a time that approximates the average performance time of Kata Gogoshiho, So that the player can perform positions within this kata to move for a long time without feeling tired, The average score of the skill level of the position that it moved from 5.23 degrees in the distance measurement to 7.84 degrees, Which confirms the improvement of the efficiency and ability of the players "research sample" on the performance of the position legs under the search technically closer to the ideal, The researcher attributed this to the proposed mental training program, which helped to develop and improve the performance of players.

These results are consistent with the findings of both Cunningham (2000) (29), Gaines (2003) Abdulmohsen Zakaria (2003) (13), Comana (2004) (28) and Ahmed Salah al-Din, Walid Jabr (2009) (25) Who emphasized that mental training through the training of mental skills Positively affects the level of ability to relax, reduce tension, Anxiety and gain control of the muscular system to achieve optimal relaxation, Which helps to 
increase the efficiency of the player to organize, guide, distribute and employ the force to produce the required movement energy, getting a The successful performance of Kata Gujochosho is under studying during the training and performance exercises.

As indicated by the results of Table (11) under study The great effect of improving the performance of the research sample in the kinetic sentence "Kata" Gogoshiho This is because the legs of the position are considered the first technical criterion to evaluate the performance of kata, Which was positively reflected on the assessment of karate rulers for the sample of research in postmeasurement, The researcher also refers to the improvement of the level of the research sample in the performance of the "Gogoshihoshu kata" to the included mental training program proposed to help young people to understand mental perception, How it occurs and how to form a mental image that the youth can conjure up with the participation of all different senses, In order to benefit from the strengthening of Kata performance in the parts of the training module, Where the mental skills training and the two men 's positions were well integrated into the training part of Gogoshihoshu $\mathrm{s}$ performance.

The same is true of Emad al-Sarsi \&Amr Halwish (2008) (15), Ahmed Ibrahim (2011) (5), Yasushi Abi (2011) (40) Of the importance of the use of different training methods to develop the speed and form of the performance of the legs of position as the backbone of the performance of "kata" in karate sport, With what he all referred to By Andrea Beller, Hale, and Lyshon (1993), 26, Ahmed Reba Radwan (2002) (1) The exercises mental visualization in a manner free of tension and a high degree of mental relaxation Of the best methods of training on the legs of positio and the development of speed and form of performance, As the reliance on physical exercises on the use of mental skills helps the player to direct all his energy In achieving athletic performance away from environmental stimuli. 
Discuss the results of mental skill variables under studying

Table (12) shows

results There was a statistically significant difference between the pre- and the post measurement in the research sample in the muscle tension in favor of pre- measurement, Indicating the high degree of relaxation in the research sample, Where the value of (T) between (11.741:17.815) a function at a significant level (0.05), The researcher attributed these differences to the proposed mental training program and the inclusion of its units of relaxation exercises The areas where tension is concentrated, such as: (neck, face, shoulders, arms, trunk, legs) Which had a great effect in reducing tension and achieve relaxation of all parts of the body, Where he confirmed Osama Rattab (2000) (6), Mohammed Shamoon (2001) (18) The player who trains on consecutive relaxation and acquires the skill of recognizing the tension in the muscles Body and then can get rid of it, especially in the positions of training and competition or in critical performance situations Can raise the rates of positive mental factors to reach the highest level of performance. (6: 184) (18: 160)

As Table (12) also indicates There were statistically significant differences between the pre and post measurements in the study sample (self-talk, mental perception components, attention concentration) for the benefit of post measurement, Where the value of $(\mathrm{T})$ between $(7.644,33.441)$ and a function at a significant level (0.05).

The researcher attributed these differences to the mental training program and its training to develop the ability to speak self, Which clearly reflect the level of selfefficacy of players (I can and can), Which stimulates their ability to perform and achieve the task towards winning and contribute effectively to improve the level of skillful performance of the (kata) in Karate sport, , As well as exercises mental perception through the dimensions of sensory (visual, auditory, sensory, motor) as well as training exercises in image control and perception of 
emotional "perception of emotions commensurate with the nature of skilled performance" In developing the juniors capacity.

These results are consistent With the findings of each study Sonijohn t (2003 )(38), Christa et al. (2005) (34), Mahmoud Abdel Fattah (1995) (21) Which indicated that the mental training programs and the training of mental perception in different dimensions Contribute to the development of skill well, The continued use of mental perception by athletes to improve their athletic skills more than others, This is also consistent with what he has explained Mohammed A. Shimon (2001) of the role and importance of mental perception in the exclusion of negative thinking and give more support, Self-confidence, increased motivation, building positive performance patterns and achieving Objectives, Which emphasizes the importance of mental perception and considered one of the main dimensions in the mental training system.
Discuss the results of the Kinematics variables in studying .

Table (13) shows the presence Statistically significant differences Between the pre and the post measurement in the Kinematics variables contributing to the degree of skill performance Of the selected movement position under study.

Indicating the impact of the content of The mental training program proposed to develop the performance of the movements of the players, From taking positions, angles, displacements, speeds and wheels during performance, This has contributed to the improved level of skill performance of Gojushiho-sho kata.

The improvement in anatomical points shows the pelvis, knee and ankle during the stages of performance as follows:

- During the payment phase to start moving: Angle displacement recorded For right hip angle $\mathrm{X}$ in the premeasurement (150.6 degrees) by 2.64 degrees, while the value in the post- measurement (163.9 degrees) by 2.87 points. 
The value of the linear wheel is also On the vertical axis of left knee a (Z) In the premeasurement $0.77 \mathrm{~m} / \mathrm{sec} 2$ and in the post $1.97 \mathrm{~m} / \mathrm{sec} 2$, Has reached Values Speed on the Y axis " lateral deviation" of right ankle-boneV(Y) In the premeasurement $-0.52 \mathrm{~m} / \mathrm{sec}$ and in the post $0.908 \mathrm{~m} / \mathrm{sec}$.

Vertical displacement was also recorded for a point right hip Z During the payment phase - to begin the move in pre measurement 1.99, and in the post 0.69 points.

The researcher is attributed to the Kinematics variables To displacementthe $\mathrm{X}$-angle of the right-hand pelvis, Acceleration on the vertical axis of the left knee, Side speed on the $\mathrm{Y}$ axis of the right ankle, And the lower vertical displacement value of the right pelvic point Are the most influential Kinematics variables and correlates with performance at the pay-to-start phase Of the three position under study, Where technical performance requires that the payment be made from the rear foot "left" To move forward, The angular displacement of the right pelvis on the horizontal axis $\mathrm{X}$ indicates the stability of the movement level And the player's success to move without any drop or rise Affect the aesthetic form of performance, It also helped change the speed of the left knee and the lateral velocity of the right ankle, To achieve the mechanical form of the stage of payment of the transfer at the maximum speed in a good harmonious and harmonious, This is confirmed by the low degree of vertical displacement of the pelvis That the player was able to change the direction of both power and speed together during the payment to achieve the best movement forward.

Hence the researcher finds that there is an inverse relationship Between each of the kinematic variables of the $\mathrm{X}$-angle displacement of the right pelvis, The wheel is on the vertical axis of the left knee, Side speed on the $\mathrm{Y}$ axis of the right ankle, And the vertical displacement value of the right pelvic point, This is consistent with what he said Jamal Alaa Eddin, Nahed AlSabbagh (2010)(7), Rogers (2000) (37) That the forward payment is semi-horizontal according to the biochemical 
rules and laws Contributes to the realization of the principle of compatibility of defenses Which in turn leads to The movement is better. (7: 145, 155). (37: 141)

- During the linking phase of the kinetic transmission: Of the three position under study, The pelvic and knee values were the most contributing to the degree of technical performance during locomotor mobility, Through the averages of Kinematics variables (vertical angle shift of the right pelvis, angular velocity of left ventricle, lateral left knee bypass) Affecting anatomical points (pelvis, knee) Right and left side, The researcher concluded that the dynamics of motor mobility of the position It depends on a high amount of motor work of the pelvis, The researcher attributed this to the nature of the technical performance of the movement of Kata players Of the need to make the greatest possible force from the center area during the move To achieve speed and torque of angular movement, And the consequent increase in the acceleration of the limbs of the body, which helps cycle motor movement ideal, Because of its importance in improving the shape and efficiency of the performance of the legs of the two men during the performance of "Kata" Gogoshiho.

- This is consistent with what both Tala Hossam Eddin (1994)(10), Husni Sayed Ahmed (1995)(8) Adel Abdul Basir Ali (1998)(11) and Jamal Mohammed Alaeddin, Nahed Sabbagh (2007) (7) Where the technical performance of the skill requires the movement of all joints of the lower body together The body has the required angular velocity in light of the biomechanical characteristics of the body, As a Kinematics chain that makes it able to change its shape to provide the conditions for achieving motor duty in good harmony. (11: 201) (10: 198) (8: 115) $(7: 145,155)$.

- during the stage of stability after motor performance: Of the three position under study Mean kinematic variables were (Acceleration on the $\mathrm{Z}$ axis of the left arm and the left knee, the lateral deviation of "Y displacement" of the right knee and right ankle, and the acceleration on the $\mathrm{Y}$ axis of 
the left knee) Are the most variables contributing to the degree of skill performance of the dynamic movement of position, The researcher attributed this to the fact that when the player stops after the performance of the situation works to reduce the speed And increase the torque of selfrestraint, allowing the player to control and control the body parts of stability with the ideal form of Kinematic position, This is illustrated by the nature of the technical performance of the second movement For the player where the focus is on the right foot and move the left, Which resulted in increased acceleration of the joint of the pelvis and the left knee, in order to achieve the rotation of the angular movement to complete the next locomotion.

- All of the above illustrates the improvement of Kinematics variables, The researcher attributed this to improving the abilities of the players "sample research" Of attention and control to focus attention on mental skills and their ability to reduce the level of muscle tension during performance, Which helped the players to speed up the technical performance of the pieces in question and then develop it to a better mechanical level.

The Results indicated of Table (14) On the correlative relationship between mental skills (muscular relaxation, mental perception, concentration of attention, self-talk) And the performance score of Gojushiho-sho kata, The calculated value of $(\mathrm{t})$ ranged between 0.677 and 0.8776 , which is greater than the value of (r) the table at a significant level of $0.05=0.514$,

Indicating that the proposed mental training program achieved the goal of increasing the ability of players to perform And motor control of position and kata under study, Since the efficiency of mental perception of the kinetic sequence of kata movements is under study Perform the players towards the performance of the kinetic sequence in a high efficiency and in the time specified for performance kata, As well as reducing negative thinking towards competition and effective control during the performance of motor sentence kata, Effectively contributes to 
better performance by increasing motivation, selfconfidence and determination towards achieving the goal of competition to win, Reducing nervous and emotional stress and thus increasing the ability to relax contribute to raising morale and developing a sense of success and victory, The ability to self-talk and the high level of self-efficacy has also contributed to the improvement of the skillful performance of the Gojushiho-sho kata.

And agree what is reached Searcher results with study Lowther James (2002)( 33), Nehal Abada, Hany Abdul Aziz (2004)(23), Ahmed AlArabi (2014)(3), With a strong correlation between selfefficacy and mental training, which includes (mental perception, concentration of attention, relaxation) And the level of skillful performance of Karate players.

The Conclusions And The Recommendations:

The Conclusions:

1- The proposed mental training program is effective in improving the performance of stands (Zenkutsu Dachi Kokotsu Dachi - Kiba Dachi) The level of skillful performance of the transitional movements of the position is under study And the degree of skillful performance of the Gojushiho-sho kata to the kata in karate.

2- The proposed mental training program is effective in the development of the most important mental and basic skills (self-talk, relaxation, mental perception, attention focus) of kata for Karate juniors.

3- Proposed mental training program Has led to the improvement of Kinematics variables the above contributing And influential in the transitional movements of the position (Zenkutsu dachikokotsu dachi-kiba dachi).

4- The cognitive program of mental and motor skills Has contributed significantly to the development of knowledge and information related to mental and motor training of juniors, He also contributed to finding a positive direction towards the mental training program.

5- attention to mental skills (relaxation, mental perception, attention focus) Because of its positive effect to reduce the level of muscle and mental tension, Understanding mental 
perception and how it occurs, And increase the focus of the player's attention to the selected stimuli.

6- There is a positive correlation relationship Positive positivity is statistically significant Between the mental skills and the level of skillful performance of kata in karate sport, As a result of the effectiveness of the proposed mental training program.

The Recommendations:

1- The importance of applying mental training programs should be taken into consideration In the light of Kinematics indicators As an essential and primary part For substantive evaluation In sports training programs for karate players and kata juniors in karate in particular.

2- Focus on the education of juniors (Kata players) How to take advantage of the use of mental skills during previous exercises of the matches to achieve the best results in overcoming the stimuli Which may lead to distraction and loss of concentration.

3- The need to pay attention to early mental training for juniors, So that mental skills programs can be used to develop and improve performance, Improve results and increase the motor performance of juniors, And raise awareness of mental trainers and their importance.

4- The need for programs by sports federations, Indicate the importance of educating educators and increasing their knowledge of the entrances to the study of sports movement, And the importance of the link between the science of mathematical movement and psychology and its relationship to the achievement of sport, As a benchmark for guidance and development of training programs.

5- Studies to identify the most important mental programs Which should be offered to juniors and adults during periods of training, competitions and negative and positive rest periods.

\section{The References:}

\section{1- Ahmed Rabea Radwan} (2002): The effectiveness of a mental training program to teach some basic skills of the originator of football, Master Thesis, unpublished, Suez Canal University, Faculty of Physical Education, Port Said. 
2- Ahmed Omar Al-Faraj AlSheikh (2016): Proposed exercises to improve the performance of Stances as one of the criteria of evaluation in international law and its impact on the level of performance of the early kinetic "kata" karate sport.

3- Ahmed Mohamed El Arabi (2014): Effect of mental training program on the level of skill performance among kumite players in karate sport, unpublished master thesis, Faculty of Sports Education, Tanta University.

4- Ahmed Mahmoud Ibrahim, Atef Mohamed Abaza (2005): Encyclopedia of the scientific and applied foundations for the planning of training programs for kinetic movement "kata" Karate sport, knowledge facility, Alexandria.

5- Ahmed Mahmoud Ibrahim (2011): Recent trends and determinants of the methods of rationing and planning of training programs in karate sport, Al-Ma'aref Establishment, Alexandria.

6- Osama Kamel Rateb: Mathematical Psychology, Concepts and Applications, (I3), Cairo, Arab Thought House, 2000.
7- Gamal Mohammed Alaeddin, Nahed Anwar AlSabbagh (2007): Movement Science, Faculty of Physical Education, Tanta University, I 9.

8- Hosny Sayed Ahmed Hussein (1992): Effect of a proposed program for the development of the "sense kinetic" cognition to improve some kinematic variables of the frontal airway in gymnastics, $\mathrm{PhD}$ thesis, Faculty of Physical Education for Boys, Alexandria University.

9- Talha Hussein Hossam Eddin (1994): the foundations of mobility and functional training sports, Arab Thought House, Cairo.

\section{0- Talha Hussein Hossam} Eddin (1994): Principles of scientific diagnosis of the movement, Arab Thought House, Cairo.

\section{1- Adel Abdel Basir Ali} (1998): Biomechanics and the Integration of Theory and Practice in the Mathematical Field, Second Edition, The Book Center for Publishing, Cairo.

12- Abdul Hakim Rizk Abdul Hakim (2010): The impact of a proposed mental training program on some 
psychological skills and performance level of basketball players with mobility, Scientific Journal of Physical Education and Sports, Volume 40, p. 73: 100, Faculty of Physical Education for Girls, Alexandria University.

\section{3- Abdul Mohsin Zakaria} Ahmed: The Effectiveness of Some Psychological Skills in Raising the Skillful and Planned Performance of Football Players, PhD Thesis, unpublished, Helwan University, Faculty of Physical Education for Boys, Pyramid, 2003.

14- Adnan Yousef Al-Atoun (2004): Cognitive and Applied Psychology, Dar Al-Maysara Publishing, Amman.

\section{5- Emad Al-Sarsi, Amr} Halwish (2008): Effect of a special training program for some kata situations in light of kinetic characteristics as an indicator of improving the performance of karate players, published research, scientific journal of Physical Education Sciences, Faculty of Physical Education, Tanta University.

\section{6- Mohamed El-Araby} Chamoun (1996): Mental training in the field of sport, 1 , Arab Thought House, Cairo.
17- Mohamed El-Araby Chamoun (2000): Mental preparation for sports competition, published article, Egyptian Association of Sports Psychology, Cairo.

18- Mohammed Al-Arabi Chamoun (2001): mental training in the field of sports, second edition, Arab Thought House, Cairo.

19- Mohamed El Araby Shamoun, Magda Mohamed Ismail 2001 (M): player and mental training, book center for publishing, Cairo.

20- Mohamed Hassan Allawi (2002): the psychology of training and sports competition, Arab Thought House, Cairo.

\section{1- Mahmoud Abdel-Fattah}

Anan: The Psychology of Physical Education and Sport: Theory and Practice, Cairo University, 1995.

\section{2- Masad Rashad Mustafa} Al-Ayouti (2004): "The impact of a mental perception program for the skill of overwhelming beating on the level of performance and some aspects of mental volleyball players under 17 years," $\mathrm{PhD}$ thesis, Faculty of Physical Education in Port Said, Suez Canal University. 
23- Nehal Salahuddin Abada, Hany Abdel Aziz Al Deeb : (2004): Performance strategies in training and competition and its relation to psychological skills of athletes (comparative diagnostic study), Journal of Comprehensive Education Research, C2, second half, Faculty of Physical Education for Girls, Zagazig University.

24- Hisham Hegazi Abdel Hamid (2000): Effect of some retroactive feeding methods on the performance of composite motor sentence, unpublished master thesis, Faculty of Physical Education, Boys Suez Canal Collection.

25- Ahmed Salah El-Din Khalil, Waleed Ahmed Gabr (2009): Mental training for enhancing attack in soccer, The 12 Issp world congress of sport psychology Marrakesh-June 17-21.

26- Andrea Blair, Hall, Leyshon (1993):: Imagery effecs on the performance of skilled and novice soccer players, Journal of sport sciences, London, Volume. II, Issue 2 April 1993, pages 95101.

27- Andrew Little (2001): Biomechanics, Western Australian Institut of sport.
28- Comana F.(2004) :

Function Training For Sports. In: Human Kinetics. Champaign IL, England.

29- Cunningham C (2000): The Importance of Quality Strength Training. In: Personal Fitness Professional Magazine, American Council on Exercise publication, April.

30- Gaines S (2003) : Benefits and Limitations of Quality Exercise, Vertex Fitness .In: NESTA, USA.

31- Hiro Kaza Kanazawa Dynamic power of karate, dragon book, Tokyo 1988.

\section{2- Jaclyn L. Salzwedel} (2009): The Relationship between Mental Trainning and Motivation in Collegiate Athletics, the Graduate Faculty University of Wisconsin Plattevill, M.D. in Education Adult Education.

33- James Lowther (2002): Self- Efficacy and Psychological Skills during the Amputee Soccer World Cup, Athletic Insight: the online Journal of Sport Psychology, 4 (2).

34- Krista j. Munroe, Chandler, Craig R(2005): Using cogitive general imagery to improve soccer strategies, European Journal of sport 
science, Volume 5, Issue 11March, pages (41- 49).

35- Nagel,-C-F. (2002): The effect of relaxation Training, Video observation, and mental imagery upon thereduction of Freestyle Swimming errors of youth Competitive Female Swimmers, Microform, thesis.

36- Nishiyama, H. and Brown, R.C. (1998) : Karate, the art of empty hand fighting, Rutland, Vermont, Charles E. Tuttle Co., Tokyo, Japan.

37- Rogers,Joseph L (2000) : USA Track \& Field Coaching Manual Human Kinetics .

38- Sonijohn, T (2003) : Effect of corrective mental imagery and error perception on learning closed motor skills, European Congress of sport psychology Copenhagen, 22-27 July, pp 170-171.
39- Vealey, R. S., \& Greenleaf, C. A. (2001): Seeing believes Understanding and using imagery in sport. In J. M. Williams (Ed.), Applied sport psychology: Personal growth to peak performance (4 ed., pp. 247-272). Mountain View, CA: Mayfield.

40- Yasushi Abe Traditional Japanese Karate, illustrating Techniques with easy terminology, 2011.

41- World karate Federation (2017): Kata and Kumitte Competition rules Effective from 1.1.2017. 